\title{
FRAMEWORK FOR A MODEL OF DIALOGUE
}

\author{
Ronan REILLY \\ Educational Research Centre \\ St Patrick's College, Dublin
}

\author{
Giacomo FERRARI \\ Department of Linguistics \\ University of Pisa
}

\author{
Irina PRODANOF \\ Institute for Computational Linguistics - CNR \\ Pisa
}

\section{INTRODUCTION}

In this paper we present a general model of communication applied to the spectal case of dialogue. Our broad perspective aims to account for the many facets of human dialogue within a single theoretical framework. In particular, our project's aim of incorporating relevant non-verbal communicative acts from the person-machine interface make it essential that the description of communication be sufficiently broad.

The model described here takes as its starting point the communicative utterance or act. It considers the higher-order structures into which communicative acts may be incorporated, but does not detail their internal composition. It is in this sense that the model provides a framework for the formal treatment of dialogue.

\section{COMPONENTS OF THE MODEL}

A full description of the adopted dialogue model has been given in Egan, Ferrari, Harper, et al. (1987). It relies on a double description of dialogue: a syntactic analysis of dialogue structure and a semantic-pragmatic description of the communication context. The basic units are:

- meaningful expression (ME): Any physical act carrying a non-contextual meaning;

communicative act (CAct): An instance of ME issued by a specific "issuer" and received by a specific "receiver";

- communicative situation (CS): The CAct together wi.th all. the relevant facets.

- communicative situation structure (CSS): A larger aggregation of "CSs that provide a bridge into the intentional component of the dialogue model.

Each of these components is discussed in more detail below.

\subsection{Communicative Acts and Dialogue Structure}

The syntactic component of the dialogue model relies on the fact that, if we examine a dialogue or any other communicative exchange, it is possible to observe in the sequence of communicative acts, subsequences which follow regular patterns. These patterns can be catalogued in a form which expresses their significant regularities. This approach leads to a descriptive method very similar to the formal description of language in terms of a vocabulary of termina1 symbols (the communicative acts), a vocabulary of auxillary symbols (a collection of labels), and a set of productions (discourse patterns). Within the definition of a communicative act, provision is made for gestural information accompanying an utterance, such as a deictic gesture involving a mouse or some other pointing device (in the context of person-machine fnteraction).

The idea of treating discourse segments like phrases in a sentence is not new (cf. Burton, 1981) However, the nature of the entities involved is rarely fully clarified. In Christie, Egan, Ferrari, et a1. (1985), a dialogue classification system was presented, based on the system of classification of Burton (1981). It consisted of a set of functional labels divided into the following five hierarchical. levels, from lower to higher,

$$
\begin{array}{ll}
\text { acts: } & \begin{array}{c}
\text { (marker, summons, elicitation, } \\
\text { reply,... },
\end{array} \\
\text { (delineating, sketching,...\}, } \\
\text { moves: } & \begin{array}{l}
\text { (explicit, } \\
\text { conversational, .... boundary, }
\end{array} \\
\text { transactions: } & \text { (exchange,...\} } \\
\text { interactions: } & \text { (transaction,...) }
\end{array}
$$

The labels at the act level are defined in terms of functional labels assigned to expressions, such as "starter", structurally realized by a statement, a question, or a conmand; "Informative" structurally realized by a statement; "elicitation", structurally realized by a question. These, together with their functional definitions, represent a closed set of elements. The labels at a higher level are all defined in terms of patterns of labels of the immediately lower leve1. This set of rules may be regarded as the set of productions, which generates communications. In this way, a dialogue/ communication is adequately described in terms of a formal generative grammar. An ATN-like grammar of dialogue in these terms has been described in Egan, Forrest, Gardiner et al. (1986) and Reilly (in press).

\subsection{Communicative Situations}

The semantic-pragmatic description relles on the notion of "communicative situation" (CS). A CS is a way of representing the communicative exchange together with its context. It consists of facets, which are aspects of the CS that occur wIth a certain regularity in all CSs of a given sort. Facets may be formally conceived of as "sorted regularities" in the scene where communication takes place, therefore a CS may be described as

$$
\operatorname{CS}=\left\{f_{s}, f_{t}, \ldots\right\}
$$

where the subscripts identify the sort of the facet.

It is relatively easy to identify the sort of the more frequent regularities, such as who the issuer is $\left(f_{f}\right)$, who the receiver is ( $\left.f_{f}\right)$, etc., and to consider these as constituent elements of a CS, around which other facets become, from time to time, relevant. 
Situation Semantics has been shown (cf. Egan, lerrar1, Harper, et al, 198\%) to have some advantages for the representation and the treatment of a CS, provided that certain modifications and extensions to the orfiginal description of a discourse situation are carried out. In communication, since more than one, and often wore than two, participants are involved, each with different attunements to the CS and different perceptions of what in situation Semantics is called the speaker's connections, more than one classification of the same CS is possible. In the best case, where partfclpants understand a CS in the same way, conmunication is successful, otherwise some failure occurs. In general we can assume, that participants in a communicative event are able first to classify, and then understand situations on the basis of the situation types they share. In the spirit of SS, we assume that these CS-types are the description of regularities observed in actual comiturications. An important consequence is that a new notion, relevance or relevant property, is established in terms of the more frequently observed regularities.

We can, then, describe the facets of the comuntuicative situation in terms of properties of that situation, where the notion of relevance Intervenes at two levels. At the first level, the set. of properties is not defined a priori. Different properties are relevant to the interpretation of different utterances in different situations. Some of these are involved more frequently than athers in the process of understanding, and may be considered more fundamental than others to a CS. These seem to be the roles of issuer, receiver, location, communication mode, illocution. The communication mode, i.e., whether communication happens face-toface, by telephone, or in any other way, may affect both the form of the message and the referring expressions. By illocution, the traditiona]. 11locutionary force is meant, al though a more finegrained classification of speech acts is intended (cf. Christie, Egan, Ferrarl, et al, 1985). Also, other facets of a CS may occasionally become relevant to the understanding of: an utterance.

At the second leve1, each property of a CS is taken to be a role particlpating in an intersecting set of regularities which qualify its sort. Thus, the property:

$$
[x \mid<<], \text { sayling, } x, \alpha>, 1>]
$$

describes some indeterminate $x$ saying $\alpha$, and participating in those situations where it is "regular" (nomic) that some $x$ stys $\alpha$.

By furthex specification we can assume that

$$
\text { [a-tourist } \mid \ll 1, \text { saying, a-tourist, } \alpha>, 1>\text { ] }
$$

paxticipates in those situations in which $x$ is of type a-tourist. In Barwise and Perry's (1.985) notation this would be given as:

$$
[x \mid \text { in } s \text { : a-tourist, } x \text {, yes] }
$$

where $s$ is the set of situation-types in which a tourdist is involved.

Both properties and types classify real objects that become relevant to a discourse situation in accordance with the relations participants are atcuned to. On the basis of this notion of relevance, it is possible to define a large set of types of properties which may or may not appear in one or the other CS. A recelver makes use of these classificatory devices to classify and understand any specific CS with which he or she is presented.

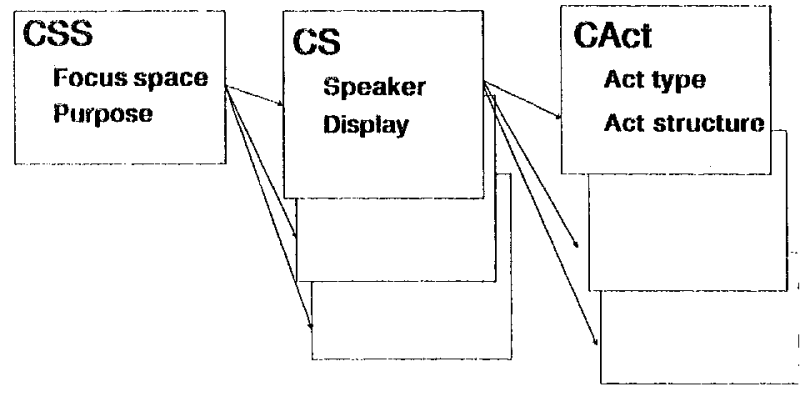

Figure 1: Structural components of the model

\subsection{Comminicative Situation structures}

The Communicative Situation Structure (CSS) is equivalent in level of analysis to the discourse segment of the Grosz and Sidner (1986) model. The three components of the CSS (see Figure 1) are the communicative act component (CAct), the communicative situation component (CS), and certain properties specific to the CSS itself. A CSS can consist of a number of CSs, and these in turn can consist of a number of CActs. The nature of CActs and CSs has already been discussed above.

A number of factors serve to distinguish one communicative situation from another. These can involve any change in the context of the dialogue; for example, a change in location or a change of speaker. In the case of person-machine conmunication it is most likely to involve a change in the speaker or a change in some aspect of the computer's visual display.

A number of communicative situations go to make up a CSS. What discingulshes one CSS from another is a change in the purpose of the CSS. The CSS is also the repository of information about what entities in the dialogue are currently in focus. This information is used in the resolution of anaphora.

\subsection{Structural Relationships}

A CSS can be related to another CSS in a limited way. The relationship can only be hierarchical, and it represents a route through which information relating to the focus of attention can be transmitted. If the focus of attention is on one CSS, definite noun phrases and anaphora in general can be resolved either from entities in focus within the current CSS or from the focus space of a cSS that is connected to the current one.

Figure 2 represents a structured collection of CSSs, As can be seen, they consist of a number of tree fragments, rather than one large tree. Such a situation can occur if the purpose of a dialogue i.s to achieve a number of distinct goals, which cannot be integrated under a dominating CSS.

\section{PRAGMATIC DIMENSIONS}

\subsection{Attentional State}

The disembodied arrow in Figure 2 represents the current focus of attention. The focus of attention sets bounds on what are valid targets for anaphoric reference within a CSS. This focus shifts automatically as a new CSS is created. It can also be shifted by one or other of the dialogue participants explicitiy requesting a shift of focus back to a previous topic in the dialogue. However, there is a constraint put on this shift. When moving from one tree fragment to another, the focus of attention can only shlft to the top-most node of the 

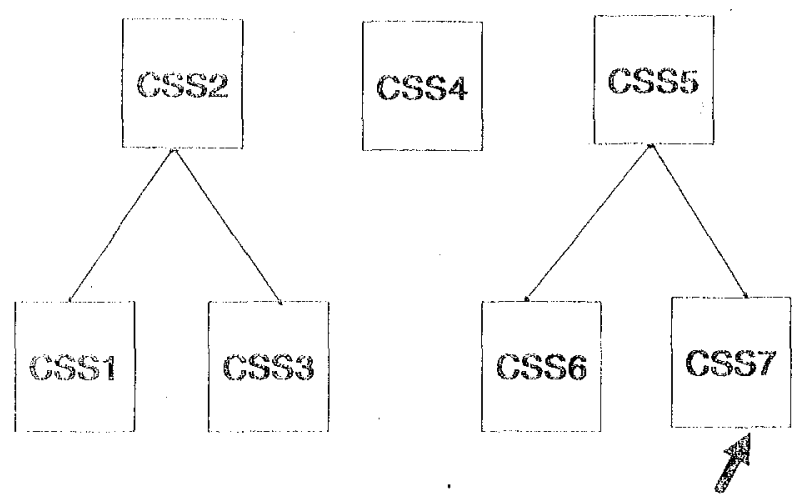

Figure 2: A set of commuricative situation structures

target wee. from there, it may traverse the subordinate nodes of the tree to locate the appropriate CSS. This restriction reflects the fact that when a dialogue participant returns to a previously active topic in the dialogue, he or she tends to proceed from the general to the specific aspect of that topic. Traversal of the cSs tree from top to bottom represents such a transition.

The component of the model operated upon by the attentional mechanism is the focus space. This consists of a list of litems that we call discourse objects. The entities on the 1.jst can efther have properties in their own xight, or can inherit then from higher up in a classification hierarchy. The reason for having highly structured objects in the focms space, is to allow for the resolution of anaphoric references of the following type (after Bidner, 1979):

\section{A: I. saw John's Irish Wolfhound yesterday}

15: Yes. They're teally big dogs.

In (B) the phrase they're does not refer back to any spocific entity mentioned in (A), but rather to tha ciass of dogs of which John's is a member. In order anceessfully to resolve this reference, knowledge needs to be arailable to the resolution process concerring the class of entrifes to which the specific Trish Wolfhound nentioned belongs, fhe way this is achieved in the model described here, is to al.low the entities in the focus space to inherit proporties via a classification hierarchy.

\subsection{Incent jonal structure}

As has been pointed out in the description of the dialogue structures, the topmost element of the structural hierarchy (the CSS) contains a pointer into a structure representing the purpose of the CSS. Grosz and Sidner refer the set of such css purposes as the intentional structure of the dialogue. In essence the cos purposes are elements in the plan underlying the dialogue. In the case of a personmachine dialogue system, they are the actions that the user wishes the systom to perform. There are two relactonships that can hold between elements of the intentional structure and these are dominance and satisfaction precedence. These represent goa1/subgoal and pre-condition relationships, respectively. The hierarchy of intentional elements is more or less isomorphic to the dialogue structure, as can be seen in lijgure 3. Here, the dialogue structure $4 \mathrm{~s}$ represented by white boxes and the underlying intentional structure by shaded boxes. Also note that the intentional. structure may be expanded by an inferential process, without there being a conresponding node in the dialogue structure.

The specific details of the intentional structure fs dependent on the dialogue domain, unlike the dialogue structure. In the following exangle of an application of the model, the donaln is that of database interaction with the user performing the specific task of cabulating data about students' ages and courses. Each intentional component representa an action of tabulation, and the place that the action has in the intentional hierarchy is determined by the complexity of the table requested (or inferred).

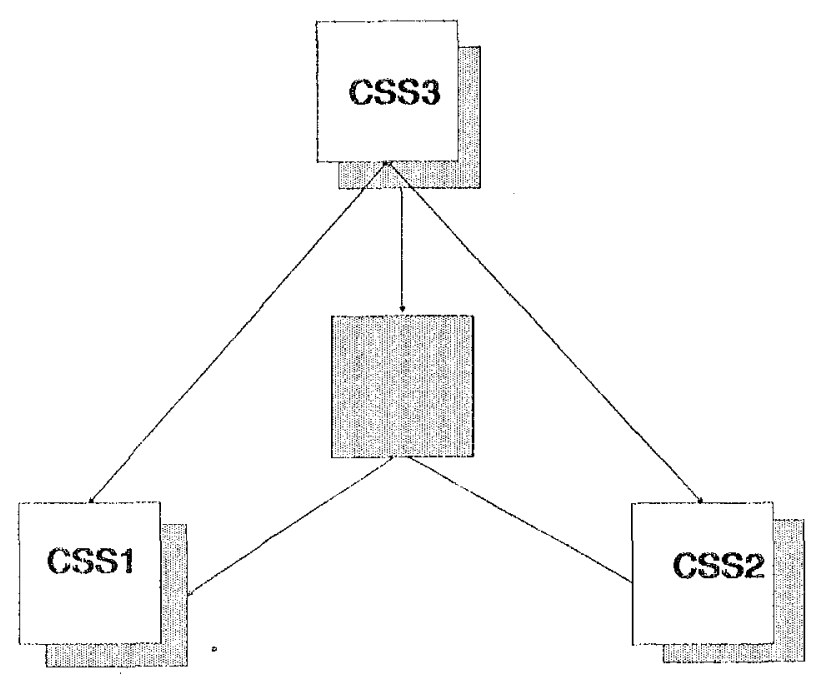

Figure 3: The relationship between dialogue and intentional structure.

\section{A SAMPLE APPLICATTON}

The following dialogue (except 58 ) was collected as part of a corpus of simulated person-machine dialogues collected for the studies described in Egan, Harris, Harper, and Reilly (1986). S8 is inserted to illustrate how an inferred intention can be used by the system to direct the dialogue.

Vl: How many students, both male and female, under 1.6 or younger in the year degree course?

S2: There are no students of that age group in the College.

U3: Again in the 3 year degree course, how many male and female students in the followirg age groups: 192021222325 or oldex

S4: Here is the table.

U5: lotal number of both male and female students in this course of study

S6: 153 males and 559 females.

07: Please supply a breakdown of both male and female students in the graduate course.

58: Do you wish to see a complete sex by age by course breakdown?

Fifgure 4 filustrates the unfolding of both the dialogue and intentional structures (the numbers in the boxes correspond to utterances). The intentional structure underlying $\mathrm{S} 8$ is inferred on the basis that the user has asked for the same breakdown for two courses, therefore he or she may wish to have a three-way breakdown for all courses. This inference then gives rise to utterance $\mathrm{s8}$, which is incorporated into the dialogue structure. The left of Figure 4 represents the state of the dialogue and intentional. structures up to and including utterance 


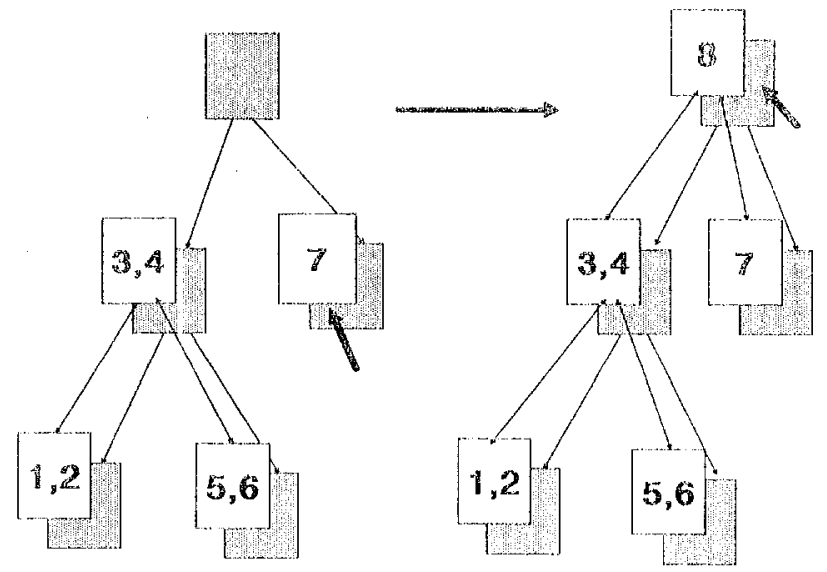

Figure 4: A Structural analysis of the sample Dialogue

U7. The right of the figure represents the structures; after $\mathrm{S} 8$.

In U5, the reference to an unspecified course (underlined) requires that a referent be found. The bi-directional links in the discourse structure allow information from the focus spaces of the connected nodes to be accessed in the resolution process. 'Thus, th: anaphoric reference in 05 can be resolved by accessing the focus space of utterances 3 and 4 .

Note thai: the small disembodied arrows in Figure 4 indicate the current attentional state of the dialogue.

\section{CONCLUSJON}

The dialogue nodel out].jned above is undex-specified in a number of important aspects. For example, no algorthinc description has been provided that can gerberate and uflise the data structures of the inode1.

The resetrch programme, of which the work described here is a paxt, is still in the early stages of implenontition. However, a number of implementation decishons have already been made which give some indication of what the final system will look like.

Both the dialogue and intentlonal structures are to be represented using a frame-based language. The frames will be connected in a network. The instantiation and interconection of the fiames will be the jub of a general control al gorithm, while the filling of many of the slots in the various frames yill be demon diven. That is, assoctated with each slot will be a function that is activated when data is requijed for the slot, such as when the frame containing the siot is instantiated. Limited use will be made of the tnheritance mechandsm of the rraue system. Inherltance will be mafnly used for the inheritance of focus-space information. The feature of frames that w111 be most utilised is that of: demon-riciven slot filling.

\section{REFERENCHE}

Barwlse, I., \& Perry, J. (1983). Sltuations and attifudes. Cambridge, MA: Bradford/MTT Press

Buxton, D, (1981). Analysing spoken discourse. In M. Coulthard, \& M. Montgoilery (Eds.), Studies in discourge tnalysia. Iondon: Routiledge \& Kegan Paul.
Ghristle, B, Egan, 0 , Ferratl, G, Gardinet, Harper, J., Relliy, R., fo Sheohy, N. (1985). De11varable 2 of: ESPRI' Project 1527; A dialogra classlfication system. Educational Researeh Centxe, Dubjin.

Kgan, O., Fexrart, G., Harpex, J., lrodenot, L. Reili.y, k., Sebastiani, F. \& Shechy, N. (1987). Del verable 7 of ESPRT project 527: ar integrated formal model of diatozie. Rducational Research Gentre, Dublin.

Egan, O., Forrext, MA., Gardiner, M, Reilly, is., Sheeky, S. (1986). DejLerble 3 of EsPd project p527: Dialogue studies - pilot plins Fducational Resenteh Centie, Dublin.

Egan, $O_{n}$, Harper, $J$, Harris, $J$, \& Reilly, R

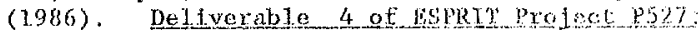
Dialogue studies main phase. libational Research Centre, Dublin

Grosz, B. (1977). The representation and use of forus in dialogue understanding. Unpublished thi thesis, University of Caltforna, Barkeley.

Grosz, 3. J., \& Sidnex, C. X.. Sidmer (1986) Attention, intentfons, and the structurs of discourse structure, Computational Linguistics, $12,1.75-204$

Reit1y R. (in press). An AlN-based gramar: to: the structural analysis of dialogue, in $\mathbb{N}$. $E$ Sharkey (Ed.), Modeling cognition: An numu!

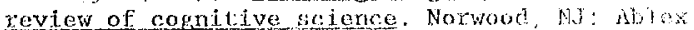

Sidner, C. L. (1979). Towad a computationa fhom

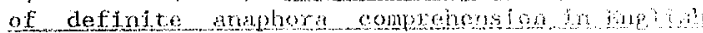

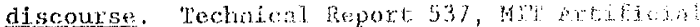

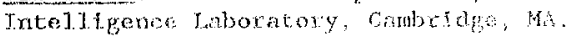

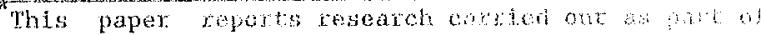

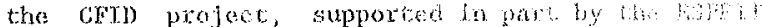
progranme of the CBC (ref. H/b4 ATt $52 \%$; 